\title{
Design Considerations for an ELeGI Portal
}

\author{
Colin Allison \\ School of Computer Science, \\ University of St Andrews \\ ca@st-andrews.ac.uk
}

\author{
Rosa Michaelson \\ Department of Accountancy and Business Finance, \\ University of Dundee, \\ r.michaelson@dundee.ac.uk
}

\begin{abstract}
ELeGI, the European Learning Grid Infrastructure, has the ambitious goal of fostering effective learning and knowledge construction through the dynamic provision of service-based contextualised and personalised learning environments. The success of this venture will depend to a considerable extent on the usability of such environments, and their usability in turn will depend on a successful strategy for the dynamic integration and maintenance of sets of services. The concept of the portal is therefore of considerable interest as it is often portrayed as a means whereby a user can access an integrated set of related information and services. This paper reviews the portal concept with a view to its suitability as a design basis for enabling technology that will address usability concerns. The paper proceeds by summarising the usability requirements of learning environments, reviewing some of the ideas currently associated with different types of portals (enterprise portals, institutional portals, usercentric portals, Grid portals), and concludes by deriving a taxonomy of portal characteristics against which the usability requirements of ELeGI can be assessed.
\end{abstract}

\section{USABILITY IN LEARNING ENVIRONMENTS}

A Learning Environment (LE) in ELeGI refers to the use of a dynamically integrated set of distributed services that are used directly by learners and teachers for educational purposes. Following the holistic approach taken to Quality of Service (QoS) in [1], Fig. 1 depicts usability requirements within a broader LE architecture.

\begin{tabular}{|c|c|c|c|}
\hline \multirow[t]{5}{*}{$\begin{array}{l}\text { Usability } \\
\text { Features }\end{array}$} & \multirow[t]{4}{*}{$\begin{array}{l}\text { Abstractions for } \\
\text { Learning Environment } \\
\text { actors }\end{array}$} & Teachers & $\begin{array}{l}\text { Users and Groups Management, } \\
\text { Educational Resource Selection and } \\
\text { Allocation, Activity Monitoring, Session } \\
\text { scheduling }\end{array}$ \\
\hline & & Learners & $\begin{array}{l}\text { Interactivity, Groupwork, High quality } \\
\text { simulations, Real-world input, Self- } \\
\text { Reflection Facilities, Privacy }\end{array}$ \\
\hline & & $\begin{array}{l}\text { Content and } \\
\text { Service } \\
\text { Providers }\end{array}$ & $\begin{array}{l}\text { Developers Application and Service } \\
\text { Interface }\end{array}$ \\
\hline & & $\begin{array}{l}\text { Service } \\
\text { Operators }\end{array}$ & $\begin{array}{l}\text { Manageability, Usage feedback, QoS } \\
\text { Feedback }\end{array}$ \\
\hline & Interface Accessibility & \multicolumn{2}{|c|}{$\begin{array}{l}\text { W3C Accessibility Guidelines } \\
\text { Output formatted appropriately for interface device }\end{array}$} \\
\hline $\begin{array}{l}\text { LE Middleware } \\
\text { and QoS }\end{array}$ & \multicolumn{3}{|c|}{$\begin{array}{l}\text { Sharing, Sessions, Security, Concurrency, Availability, Replication, Distribution, Coherence, } \\
\text { Responsiveness, Timeliness, Interoperability, Resource Management, Resource Discovery } \\
\text { and Location, Security, Identity Management }\end{array}$} \\
\hline \multirow[t]{2}{*}{$\begin{array}{l}\text { Low-level } \\
\text { Infrastructure }\end{array}$} & \multicolumn{3}{|c|}{ Network Protocols, Operating Systems, Client-Server, Peer-to-Peer, Mobile Services, } \\
\hline & \multicolumn{3}{|c|}{ Physical Networks, Computers, and Interface Devices } \\
\hline
\end{tabular}

FIGURE 1: Usability Features within an EleGI Learning Environment Support Architecture 
Firstly, major roles are identified with respect to a LE: institutions, teachers, learners, subject-specialists, service operators, content and service providers. Secondly, appropriate abstractions are determined by requirements analysis of each role, and groups of LE actors. Note that this approach also supports evolution of novel learning scenarios through continuous re-analysis of the principal roles and requirements, and as LEs evolve with changes in pedagogy and advances in technology. When this is done we can evaluate usability for learners from two viewpoints: i) the extent to which the LE middleware can dynamically realise usability features on top of a particular low-level infrastructure context; and ii) the extent to which the actual end-user access points can deliver these features. While the OGSA framework appears ideal for the research, development and deployment of LE middleware, it does not directly address user interface and usability issues per se. Therefore it must be complemented by a user interface management methodology and set of mechanisms, and this is exactly where the portal concept is of particular interest.

\section{THE PORTAL CONCEPT}

The general purpose of a portal is to provide a single access point to a range of related information and services. It is widely used by commercial public web-based service providers in order to reduce the time that individuals spend searching, although it only promotes options that are commercially sponsored. Such portals sometimes offer facilities for personal customisation - for example, a user can specify an interest in specific types of sporting events or the local weather forecast. Examples of this approach include MyYahoo!, Lycos and MyNetscape [2-4]. However, the customisation options are very limited and, most often, these types of portal cater for anonymous users.

In contrast, the Enterprise portal is a non-public portal, which provides a type of shared corporate desktop customised for each employee. In a recent survey [5] of the US commercial sector $87 \%$ of the respondents believed that enterprise style portals would "eventually constitute the main window through which users are able to access multiple, heterogeneous software applications, along with relevant content and analysis." This type of portal is usually the front-end for an application server, which integrates various company databases and applications. While enterprise portals are customised to some extent for employees, this is mostly along the lines of which department or project they are working in/on.

In the education domain the concept of the Institutional portal is attracting attention. This is expanded and expounded in [6] where it is argued that (unlike the Enterprise portal) such a portal must be non-proprietary and under the full control of the institution it represents. The 2003 survey of the U.S. Campus Computing Project has documented the growth of institutions that have Web-based campus portals from 21.2 percent in 2002 to 28.4 percent in 2003 [7]. The institutional portal distinguishes three main content-oriented views of the institutional information base: hierarchical web pages, audience web pages and the personal web portal.

- Hierarchical pages are designed for anonymous, casual visitors, and are generally read-only with limited query facilities. They may be searched and traversed according to a number of themes: studying at the University, Research at the University, and so on. Many institutions already provide this type of view.

- Audience pages are targeted at specific groups such as existing students, alumni, academic staff, technical staff, and so on. Access may be restricted via an allocated password. The tenor is still predominantly readonly, but facilities such as chat and e-mail exchange may be provided. Several institutions offer this type of web service.

- Personal pages are intended to go much further than the audience pages by specifically targeting each individual. This is rarely provided at present, and represents a non-trivial technical challenge.

The combination of these three views mandates a common portal reference framework. uPortal is one such framework. It is an Open Source software product sponsored by the Java in Administration Special Interest Group JA-SIG [8]. MyOneStop [9] and MyBytes [10] also claim to address this need. In the UK Higher Education sector several Universities have recently rallied round the uPortal flag [11] and abandoned efforts to create their own extensible portal technology, or to adapt proprietary commercial products.

Finally, the portal concept has been developed and exploited by Grid developers since 1997. Examples include many subject-specific portals built with the Grid Portal Developers Kit[12], and the Gridport toolkit [13]. The abundance of Grid portals is evidence of what is explicitly acknowledged in most Grid communities - that having sophisticated middleware and formidable low-level computational and network infrastructure is pointless if facilities cannot be accessed and utilised in a convenient and intuitive fashion. So, to a large extent, the take-up of Grid technologies beyond a relatively small group of users who are au fait with pseudo-cryptic job control commands and scripting languages, is dependent on the development and deployment of useable interfaces, and this is what is expected from portals. Grid portals to date however, have been built to support clearly identifiable communities 
from toolkits. They do not appear to offer the flexibility of uPortal which can change its appearance and functionality in response to requirements without involving low-leve toolkit programming.

\section{BEING USER-CENTRIC}

As previously noted, a significant technical challenge for portal frameworks is the support of usability through relevance - that is, the production of a "personal portal" which is dynamically tailored and maintained for each individual. We refer to such portals as user-centric as they are built entirely around the identity of the user. In the traditional, institution-based, educational domain a user-centric portal should gather and present all the information and services necessary for the lecturer, based on their institutional roles. Similarly, a student should find only information that is relevant to their academic work. MMS [14] is an example of a role-based user-centric portal that has been built to operate in a traditional educational institution environment. An example MMS scenario is shown in Figure 2.

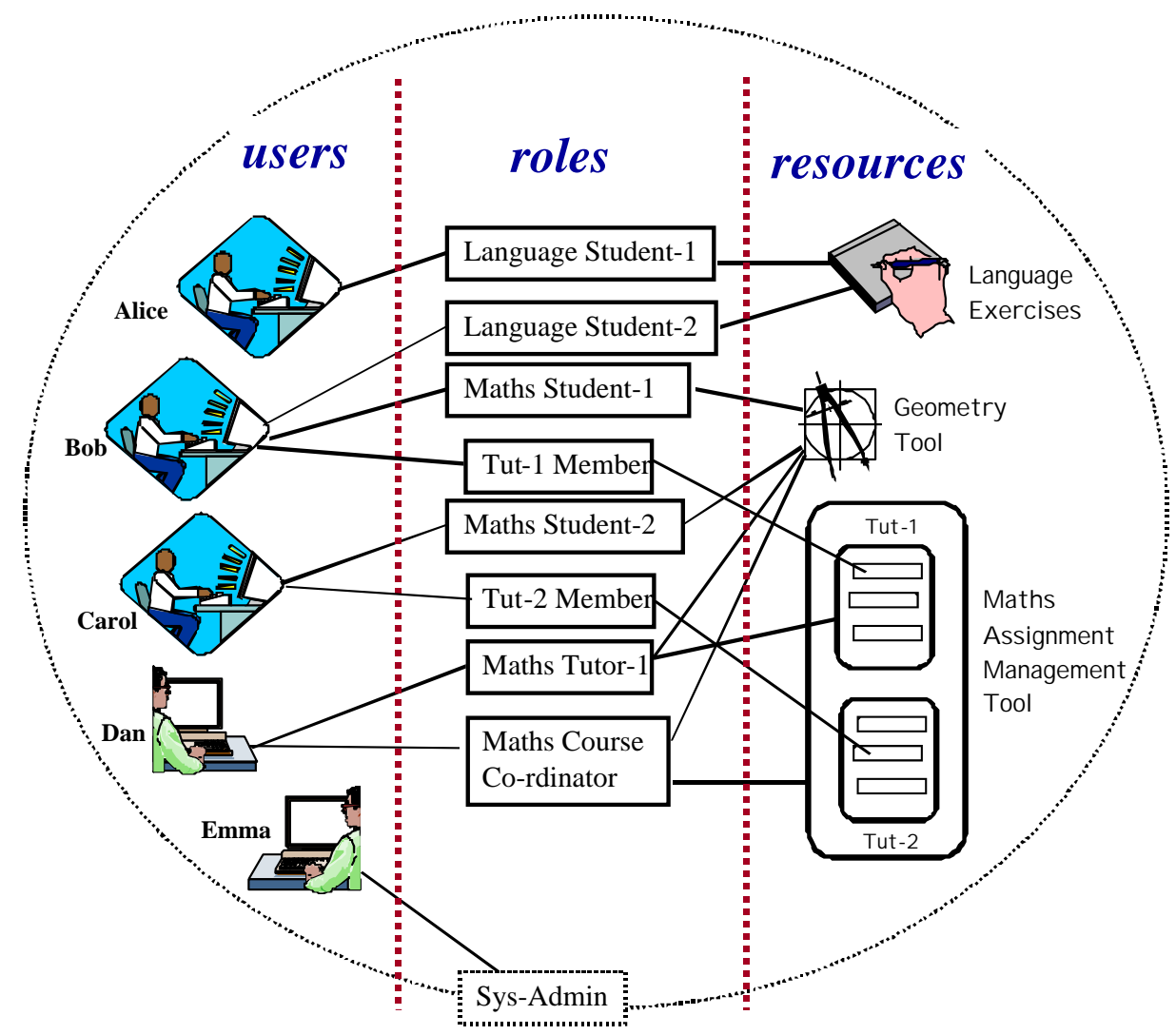

FIGURE 2: Role-based User-centric Views

In Fig. 2 each user has their own LE. This simple example scenario features five users: three students, an academic staff member, and a systems administrator.

- Alice is only taking a language module and only sees a set of interactive language exercises.

- Bob is taking Languages and Maths. He sees the same language exercises as Alice, a Geometry tool, and an assignment management tool for handing in work, and receiving marks.

- Carol is only taking Maths. She sees the Geometry Tool, plus her own part of the assignment manager.

- Dan is both a Course Co-ordinator and a Maths Tutor. He takes Tutorial Group Tut-1. He sees the Geometry Tool, a view of assignments limited to his own tutorial group, and also a view of the whole class, useful for a course co-ordinator.

- Emma is a systems administrator, and can, in principle see anything in the combined set of LEs. This does not preclude a resource type from providing its own privacy mechanisms.

The customised view delivered to each user in Fig.2 is based on their roles, and the qualification of the relationships between these roles and resources, based on the privileges associated with each role, and the users identity. User-centric portal generation and maintenance is a key component of MMS, and a relatively advanced 
example of personalised customisation within an educational domain. MMS is based on earlier work carried out by the TAGS [15] and INSIDE [16] projects. It does not in itself fulfil the needs of ELeGI, but is an important contributing technology.

\section{A TAXONOMY OF PORTAL CHARACTERISTICS}

The portal concept is not precise, and there are quite different approaches visible in the categories briefly reviewed in this paper - public portals, Grid portals, enterprise portals, institutional portals, user-centric portals.

\begin{tabular}{|c|c|c|}
\hline Portal Feature & Commentary & ELeGI? \\
\hline $\begin{array}{l}\text { Customised for the } \\
\text { user }\end{array}$ & $\begin{array}{l}\text { The portal recognises the user and accesses a profile to determine what } \\
\text { types of services and information is relevant for them, and possibly other } \\
\text { preferences such as presentation format. }\end{array}$ & $\mathrm{Y}$ \\
\hline $\begin{array}{l}\text { Customisable by the } \\
\text { user }\end{array}$ & $\begin{array}{l}\text { The user may: i) select from optional services and content; ii) choose a GUI } \\
\text { look and feel; iii) organise a preferred layout. }\end{array}$ & $\mathrm{Y}$ \\
\hline Anonymous access & $\begin{array}{l}\text { Part of the portal vision is a way of evolving existing institutional web sites, } \\
\text { so an anonymous visitor is presented with significant chunks of information, } \\
\text { hierarchically organised, as is presently done in most public institutional } \\
\text { web sites. }\end{array}$ & $\mathrm{Y}$ \\
\hline $\begin{array}{l}\text { Anonymous } \\
\text { subscription }\end{array}$ & $\begin{array}{l}\text { An anonymous user can request an account and create their own } \\
\text { username and password. They may be able to subscribe to e-mail } \\
\text { notifications of specific types of event, or partake in group activity. This is } \\
\text { not generally supported by current institutional web sites. }\end{array}$ & $\mathrm{Y}$ \\
\hline Single Sign-on & $\begin{array}{l}\text { A user can use their institutional username and password, or certificate, to } \\
\text { access the portal. All subsequent accesses to information and services } \\
\text { within the portal are then trusted as the portal handles the authentication } \\
\text { and access control issues. }\end{array}$ & $\mathrm{Y}$ \\
\hline $\begin{array}{l}\text { Application Server } \\
\text { (Implied Read-Write) }\end{array}$ & $\begin{array}{l}\text { The Enterprise portal is seen as a means of controlling access to approved } \\
\text { corporate software, data and schemata. In contrast to most web sites, } \\
\text { which offer basic HTML supported interaction options, portals offer genuine } \\
\text { two-way, read-write access to services and data repositories. }\end{array}$ & $\mathrm{Y}$ \\
\hline Content Aggregation & $\begin{array}{l}\text { Content is regularly copied and updated from diverse information sources. } \\
\text { These may be existing web sites, databases, online directories and so on. } \\
\text { It may be copied as low-level data and then extensively formatted for } \\
\text { presentation in the portal. }\end{array}$ & $\begin{array}{l}\mathrm{N} \\
\text { pre-GRID } \\
\text { feature }\end{array}$ \\
\hline Content Proxy & $\begin{array}{l}\text { Rather than copying, re-organising, formatting and presenting data from } \\
\text { external sources (as is the case with content aggregation), the portal } \\
\text { maintains a dynamic link, as an inline frame under a tab, from an external } \\
\text { source, typically a web site. }\end{array}$ & $\mathrm{N}$ \\
\hline Content Referral & $\begin{array}{l}\text { This is the simplest and least impressive portal capability: a standard } \\
\text { hyperlink or URL. }\end{array}$ & $\begin{array}{l}\mathrm{N} \\
\text { pre-GRID } \\
\text { feature }\end{array}$ \\
\hline $\begin{array}{l}\text { Support for Multiple } \\
\text { Device Interfaces }\end{array}$ & $\begin{array}{l}\text { Can the portal recognise or adapt its output to interface devices other than } \\
\text { the standard web browser? For example, handheld computers and mobile } \\
\text { phones. }\end{array}$ & $\mathrm{Y}$ \\
\hline $\begin{array}{l}\text { W3C Access } \\
\text { compliant }\end{array}$ & $\begin{array}{l}\text { Does the portal ensure that the organisation, formatting and presentation is } \\
\text { consistent with W3C recommended access guidelines? Failure to do so } \\
\text { may disadvantage users with special needs, and may contravene } \\
\text { legislation. }\end{array}$ & $\mathrm{Y}$ \\
\hline $\begin{array}{l}\text { Sole point of access } \\
\text { to information } \\
\text { services }\end{array}$ & $\begin{array}{l}\text { Something of a holy grail, and more than a little paradoxical. If a portal is } \\
\text { being used as an integration mechanism, can it also expect to supplant all } \\
\text { the other existing front-ends to diverse information services and content } \\
\text { repositories? The problem about a portal trying to sell itself as a "one-stop- } \\
\text { shop" is that unless it really is, it is simply another manifestation of the } \\
\text { problem it claims to be solving. }\end{array}$ & $\mathrm{Y}$ \\
\hline Secure & $\begin{array}{l}\text { As the portal may provide access to private, or sensitive, or licensed } \\
\text { information and services, security of access is seen as essential. Indeed, } \\
\text { most countries have some form of legislation that places a duty of } \\
\text { reasonable care on service provider who hold personal data. }\end{array}$ & $\mathrm{Y}$ \\
\hline
\end{tabular}

TABLE 1: Characterising a Portal 
Table 1 outlines a taxonomy of portal characteristics which provides a common framework for comparing different portals and portal frameworks. Space limitations preclude a complete set of comparisons, but the right hand column is used to note where a feature is likely to be of particular value to an ELeGI portal.

\section{CONCLUSION}

Usability without usefulness is pointless. A crucial usability feature of an LE interface is the relevance of the content and services it provides for each user. This means that the content and services delivered must be constructed, and then maintained dynamically, around the identity of each user, in their current context. ELeGI portal technology aims to combine personal profiles with middleware services to ensure that only relevant content and services are delivered to the end-user, in the appropriate format for their current interface device. This is a significant technical challenge. Fortunately, methodologies and mechanisms for building Grid portals and Usercentric portals have been made extant through design and implementation experience in projects such as TAGS, INSIDE and Gridport, and this work provides a solid foundation for meeting the challenge that lies ahead.

\section{REFERENCES}

1. Allison, C., et al. (2001) An Holistic View of Quality of Service. Interactive Learning Environments. 9(1).

2. Yahoo (2003) www.yahoo.com/.

3. MyNetscape (2003) my.netscape.com/.

4. Lycos (2003) www.lycos.com/.

5. Buxbaum, P.A. (2002) "It's difficult to get a clear view of portal concept". searchebusiness.techtarget.com/originalContent/0,289142,sid19 gci779661,00.html.

6. Gleason, B.W. (2001) Institutional Information Portal Key to Web Application Integration. crayfish.mis.udel.edu/maria/uportal/whitepaper2001.pdf. JA-SIG.

7. CCP (2003) Campus Computing Project, National Survey of Information Technology in US Higher Education. www.campuscomputing.net/.

8. JA-SIG (2003) http://www.ja-sig.org/.

9. MyOneStop (2003) https://myonestop.umn.edu/mos/PortalGeneric.jsp.

10. MyBytes (2003) www.mybytes.com.

11. Kraan, W. (2002) Open uPortal technology gains ground in the UK, CETIS. www.cetis.ac.uk/content/20021126163827.

12. Novotny, J. (2002) The Grid Portal Development Kit. Concurrency and Computation: Practice and Experience. 14(13-15): p. 1129-1144.

13. Thomas, M., et al. (2001) The GridPort Toolkit Architecture for Building Grid Portals. in 10th IEEE Intl. Symposium on High Performance Distributed Computing. August 2001. IEEE.

14. Allison, C., et al. (2003) MMS: A User Centric Portal for eLearning. in 14th Intl. Workshop on Database and Expert Systems Applications. August, 2003. Prague, Czech Republic: IEEE CS.

15. Allison, C., et al. (2000) The TAGS Framework for Web-Based Learning Environments. in Web Based Learning Environments. June 2000. Portugal: University of Porto, FEUP Editions.

16. Allison, C., et al. (2003) Addressing Academic Needs in Managed Learning Environments. in 4th Annual LTSN-ICS Conference. August, 2003. Galway, Ireland. 